\title{
Blowing Your Own Trumpet: How to Increase the Online Visibility of Your Publication?
}

\author{
Sumaira Khalil ${ }^{1}$, Devendra Mishra ${ }^{2}$ and DeEpika UpadhyaY ${ }^{3}$ \\ From Departments of Pediatrics, ${ }^{1}$ Vardhman Mahavir Medical College and ${ }^{2}$ Maulana Azad Medical College, Delhi; and \\ ${ }^{3}$ Department of Commerce, Christ University, Bengaluru, Karnataka; India.
}

Correspondence to: Prof. Devendra Mishra, Department of Pediatrics, MAM College, Delhi 110002.drdmishra@gmail.com

\begin{abstract}
After seeing one's manuscript in the print form in a journal, the author feels a sense of elation which is indescribable. However, if one really want peers and other researchers to take note of the work, some more effort is needed. With the massive increase in the number of biomedical journals in print - supplemented by another large chunk online - quite a few published papers remain unread by majority of the readers. The availability of social sites, persistent identifiers, and manuscript-sharing sites has simplified the job of increasing the impact of an article. We herein share some of these tricks-of-the-trade.
\end{abstract}

Keywords: Author version, Copyright, Impact, Persistent identifiers, Social network.

A

fter sustained efforts leading to the completion of the research-work and its acceptance and publication in a journal, the authors heave a sigh of relief and plan to enjoy the moment. However, be aware that some more effort is still needed to ensure that the publication receives the attention of other workers in the field and gets maximum visibility. Millions of research papers are published every year [1], both in print and on the Web finding the ways of increasing the visibility of your scientific work is of utmost importance.

With increasing access to the internet, avenues for dissemination and accessibility of research have widened significantly. Online portals and websites are increasingly becoming a tool for promoting one's research publications to attract more readers and professional colleagues - thereby expanding your professional network. We herein discuss some of the common ways to enhance the visibility of an accepted/published research paper among other researchers and also lay persons. The cornerstone of this strategy is to be aware of this need for wider dissemination early on, and start working for it from the stage of article preparation itself.

\section{During Manuscript Preparation}

\section{Choosing the Journal}

Choosing the right journal for publishing your paper is the first step towards reaching your target audience. This important decision must be made before you start writing your article, and has already been discussed in a previous article of this series [2]. Springer's Journal Suggester (www.journalsuggester.springer.com), Elsevier's Journal Finder (www.journalfinder.elsevier.com) and Journal guide (www.journalguide.com) are some tools available online that will help you to choose the most suitable journal for your research. Find My Journal (www. findmyjournal.com) is a free-software that indexes all major publishers and provides a wide database to search the most appropriate journal to publish your research work, once you provide some information about your paper.

Open-access journals: Research shows that citations of a published paper increases by $10 \%$ if published in an Open access journal $[2,3]$. Open access (OA) journals are online journals with free subscription where the cost is incurred by the author for publishing, and it gives full online access of all the articles. Articles published in open access journals are available free full-text to all readers. Some limitations of OA journals are the increasing prevalence of ghost journals and predatory journals [4], which has already been addressed in detail [2].

Indexed journals: Articles submitted in indexed journals are considered to have higher scientific quality as compared to non-indexed journals, thereby increasing their readership. There are numerous indexing services like EMBASE, SCOPUS, SCIRUS, Medline and EBSCO Publishing electronic databases [5], and authors need to ensure that the journal is indexed in a reputed and acceptable database.

E-publication ahead of print: Some journals have a policy 
of publishing accepted papers on their website, prior to their scheduling for the print issue. These are posted to the website for making them available to readers, ahead of their publication in print (though the text may undergo some changes in the final version after proof-reading). Publication in such journals makes your accepted manuscript available online very soon after acceptance, thereby precluding the delay till print issue.

\section{Title and Abstract}

The Title and Abstract of an article are most commonly used by the indexing systems and databases for conducting literature search, as has already been detailed [6]. Writing a search engine-friendly Title and Abstract can be one of the ways of ensuring the visibility of your paper to a wider audience [6]. Thus, write a concise and interesting description (50-100 words) emphasizing the prudent points, and anything new added to the existing knowledge as Abstract. Structured abstracts are preferred by most journals but various innovations have also come up in recent times:

Graphical abstracts: This is a "single, concise, pictorial and visual summary of the main findings" [7]. These graphical abstracts can be used for promoting your article by tweeting it, sharing on social media, or adding a link to your article. Detailed information regarding graphical abstracts is available at various journal websites.

Video abstracts: Some journals also ask for a video abstract, linked to the e-version of the paper once they are accepted for publication [7]. These are about 5-minute videos describing the main aim and results of the paper using animation and graphical representation. Tips to prepare a video abstract are also available at the author services pages of many publishers.

Tweetable abstracts: Some journals, apart from traditional abstracts, also ask for a tweetable abstract [7], comprising of a summary of the aim and results of the study in about 100 words. This facilitates rapid dissemination of information to a wider audience.

\section{After Publication}

After the publication of the article, the authors' efforts should be directed to ensure that it reaches the widest possible (and most appropriate) audiences. This can be done by making it available on the Web, and sharing information about it through social networks and professional networks.

\section{Using the Worldwide Web}

There are innumerable opportunities on the Web for disseminating information about your published paper, and sharing it with interested professionals (Box 1).

\section{BOX 1 Highlighting Your Article on the Web}

- Talk about your research on social media e.g., blogs, Facebook.

- Share your e-print link with your networks.

- Add a link to your article on your email signature.

- Add your article to reading lists.

- Post a link to your article on your profile on all professional or academic networks you're a member of.

- Put a link to your article on your institutional profile page, your personal webpage or any project websites.

Using personal e-mail: You could very well include your article in your email signature. Some journals even provide a free service for preparing a banner related to your paper, so that it can be placed at the bottom of all your e-mails. As many of the persons you correspond by e-mail are also working in the same field, this method is most likely to reach a relevant audience. In addition, a short message (with/without a link) can also be posted to any discussion lists or Listserves you are a member of.

Online repositories: These are created by single institutions, cross-institutional or departmental; where members of the institution can deposit their research work; which is freely accessible. Institutional repositories preserve and disseminate the research output of the institution in the form of digital copies of major research projects, dissertations, published papers of faculty, etc. at the institutional website for free access by other researchers. The contents available are mainly theses, unpublished research projects, pre-prints, postprints and research reports and does not undergo a peer review process e.g., D Space is a repository created by the Massachusetts Institute of Technology to manage and disseminate all the research and intellectual output from the university [8].

Even if your departmental/institutional website does not currently have an archiving system, you can still use the institutional website to embed links to your published paper.

Social Science Research Network (SSRN): The Social Science Research Network (SSRN) is a popular website which provides for dissemination of research papers and scholarly work in the area of social sciences and humanities. It is an open access repository for the scholarly community wherein articles/papers can be uploaded for free access by those who have an account on the website. 
The functioning of Open access repositories can be monitored by Registry of Open Access Repository (ROAR) and Open Directory of Open Access Repository (Open DOAR) [9]. One should utilize repositories to make available their published paper (even if it is only in the abstract format), as this practice leads to a wider access to the research, thereby increasing its visibility. However, before sharing the full-text of your published paper on any such website, do check with the journal where it is published - many journals do not permit archiving of full-text articles, not even self-archiving!

Self-archiving: One of the ways of self-archiving accepted article is through creation of personal websites that makes the article open access, thereby increasing its impact and citations. Personal websites are created by individual researchers where they post information regarding their article along with their personal details, a Curriculum Vitae, list of publications, research interest, experience and expertise, and research projects and conference presentations [10]; thereby, making it a channel that projects their work. It has been found that open access repositories have a lower proportion of citations [11] as compared to personal websites, but the effectiveness of such self-publishing is questionable [12]. There could be varied reasons for creating personal websites, for expression of identity, self-presentation or even entertainment quotient $[13,14]$. Again, the issue of copyright crops up, as many journals do not permit this self-archiving of the published paper (and they hold the copyright!).

Search engine optimization (SEO): Web-based search engines like Google scholar, Microsoft academic search, Elsevier's Scirus, SciDiver, IEEE Xplore, SciPlore.org and others are commonly used for searching academic articles. These search engines index PDF files of academic articles making it freely accessible online, thereby increasing its visibility [15]. However, with the presence of web spams, the citation counts on google scholar must be taken with a pinch of salt. By optimizing your articles, you guarantee that your articles are indexed and gain a higher ranking in general and academic search engines. SEO of an article helps to keep your article on the top when someone runs a related search on search engines like Google. This leads to greater visibility amongst readers and potentially more citations [16].

There are several ways you can optimize your article for better indexing and ranking in search engines. Using strong keywords and synonyms (preferably incorporating Medical Subject headings from PubMed), the location in the text of these keywords (i.e., in a title $v s$. only in a subheading), the completeness of the metadata, the use of vector graphics for your graphs, and having a public group for your research, are some examples of the techniques [17].

\section{Using the Social Network}

With the extensive use of internet, social networking has become one of the most common media for projecting your research work (Box 2). Many researchers post their work on Facebook, Twitter, WECHAT, etc. for widespread visualization, awareness, to start interesting discussions and increasing visibility. Blogs are also an important and very effective way of disseminating information about published research. Using the social media, in addition to disseminating your research to your social circle, is also a good way to reach the lay public, interested patients, and even media personnel, sometimes leading to mention in the media publications, if it is a newsworthy research.

There are multiple scientific social networks like Research gate, Linked in, Mendeley and Academia.edu. In these academic networking sites, apart from projecting your research work, you can also build a complete picture of your professional achievements and research interests.

Research Gate: Research gate is one of the more popular scientific social networking website where you can read and share publications, create personal profile for sharing your research work from the project-stage till they are accepted for publications, and is an excellent platform for generating discussions [18] and connecting with other academicians; thereby, making your research visible. Researchers must have a user ID with the website through which they can freely upload their articles/working papers/conference papers and scholarly works for free access by other users. Research gate also has its own citation impact measurement in form of RG Score. In recent years, it has been noted that many article published

BOX 2 Writing About Your Research on the Web

- Remember, non-professionals and general audience may also read your post.

- Keep the language as simple and jargon-free as possible.

- Avoid over-simplification of study-implications.

- Avoid inflating the importance of yours findings.

- Provide links to supporting material and your institutional/personal websites.

- Tag friends, colleagues, and other researchers in the same field.

- Provide figures / illustrations / pictures; they generate interest. 
in 'ghost' or 'predatory journals' are also visible on Research gate, highlighting the poor reliability of such websites [19].

SciENcv (Science Experts Network Curriculum Vitae): The National Center for Biotechnology Information (NCBI), in addition to the PubMed, also provides a researcher profile system for researchers who apply for, receive or are associated with research investments from US federal agencies. SciENcv is available at My NCBI on the NCBI website (https://www.ncbi.nlm.nih.gov/ sciencv/).

Atlas of Science: This is another free website that aims to disseminate scientific information, especially the researcher's own perspective on the results, to the general public at a faster speed. This, by-invitation service, permits the researcher to write and publish a short lay summary of their peer-reviewed published article (including illustrations), which is then available at the Atlas of Science website [20]. The service is free to both the authors and the readers.

Kudos is another free web-based service that helps researchers increase the visibility and impact of their publications, in addition to providing the facility of providing short lay person summary of research for sharing with various website. Various article metrics are also provided (https://www.growkudos.com/about).

\section{Using the Journal's Services}

Once a manuscript is accepted by a journal, the journal has an almost equal stake in the increased visibility and citation of the article. Thus, most journals have developed various mechanisms for increasing the visibility and accessibility of the published article, and their help pages guide authors on utilizing these. Some of these are:

E-prints: Providing e-prints of the published paper is a method of increasing visibility of accepted articles e.g., authors of any article published in a Taylor and Francis journal get a limited number of free e-prints to share with their colleagues in order to enhance its visibility [21]. Eprints can also be shared by linking it to one's e-mail or posting it on one's twitter account or Facebook; the link provided by the publishers continues to work after the free access allowance is reached, but then it directs people to the abstract page. Another example is the Springer Nature Content Sharing Initiative using a SharedIt link, wherein additionally, the readers are also able to use Enhanced PDF features such as annotation tools, one-click supplements, citation file exports and article metrics [22]. Some journals even provide this free e-Offprint along with the final cover of the respective issue, making it more attractive for sharing.
Persistent identifiers: These are unique numbers/ alphanumeric identifiers for scholarly works, either a journal (e.g., ISBN) or an individual article (e.g., PMID used in PubMed). These are "enduring references to a resource such as a web page, file, image, or other (usually digital) object" [23]. Persistent identifiers can also be used to locate either the resource or information about the resource - usually by using it as a URL. A Digital Object Identifier (DOI) is one such adapted identifier system that provides alpha-numeric identifiers that can be turned into a URL. However, it is a paid system, whereas the Publisher Item Identifier (PII) is another one which is free to use by journals, and is also used by a number of scientific journal publishers [24]. It uses the preexisting ISSN or ISBN of the publication in question, and adds a character for source publication type, an item number, and a check digit.

Persistent identifiers can also be obtained by individual researchers (unique researcher identifiers). Open Researcher and Contributor ID (ORCID) links to an individual's research output and helps in distinguishing researchers from each other [25], and is being increasingly used by journals, institutions and recruiters. Other such identifiers include Researcher ID (integrated with Web of Science) and Scopus ID.

Direct link to social media: Some journals provide a direct link to Facebook/Twitter/Pinterest etc. directly from your published paper at their website. Thus, the author is saved the hassle of writing a message and embedding the link to the article at these sites - all this is available readymade at the click of a button.

Delineated contributor roles: Although not strictly a method to increase visibility of the article, detailing standardized contributor roles with the article increases the visibility of the individual authors, especially in relation to their core competence with respect to the publication. Some journals, e.g., Medicine, have integrated CRediT (Contributor Roles Taxonomy) into their submission system, enabling more transparency to the published work and allowing individual authors to get credit for their specific contributions to the manuscript. The system provides a list of 14 author's contribution roles for selection with each author's name, with more than one contribution permitted for each author [26].

Over the years, the pressure on researchers is not just limited to publishing the research - it has gone on to creating an impact and demonstrating that impact (by citation metrics etc.). With the availability of online media and social network, there are numerous tools available to make your presence felt and increase the visibility of your research, which indirectly increases 


\section{BOX 3 Increasing a Publication's Visibility}

\section{During manuscript preparation}

- Choosing the journal

o Best match for your subject-area

o Indexed journal, preferably with e-publication ahead of print

- Title \& Abstract

o Write a search-engine-friendly title and abstract

o Use facility for graphical/video/tweetable abstracts

\section{After publication}

- Using the web

o Personal e-mail: Share, use article link as a mail header

o Online repositories: Upload abstract/full text at such repositories

o Self-archiving: Upload link at your personal, or institutional website

o Search engine optimization: Optimize your article for identification by search engines

- Using the Social Network: Use your social network to discuss your research.

- Using the Journal's Services: Enquire about and utilize the journal's author services for increasing your publication's visibility.

your citations and helps in expanding your professional network. But these methods also come with their share of drawbacks in the form of ghost journals and web spams. We have discussed a good selection of the armamentarium at your disposal (Box 3), though new ones would be available by the time we are in print; it is up to the authors to remain updated. The right balance between good scientific vigor in research and awareness of modalities to disseminate it will help a researcher in making a stronger academic reputation in the future.

Contributors: SK: Literature search and preparation of the initial draft; DU: Search of the Worldwide web for related sites and intellectual contribution to the manuscript preparation; DM: Conceptualization of the idea and preparation of the final manuscript. All authors approved the final manuscript.

Funding: None; Competing interest: None stated.

\section{REFERENCES}

1. Jinha AE. Article 50 million: An estimate of the number of scholarly articles in existence. Learned Publishing. 2010;23:258-63.

2. Dewan P, Shah D. A writer's dilemma: where to publish and where not to? Indian Pediatr. 2016;53:141-5.
3. Jayaprakash K, Rekha AP, Rajendiran S. Open access journals-A study. IOSR J Human Soc Sci. 2013;8:7-9.

4. Mirjana I, Miloš R, Vladimir K, Jovana V. Computer science and information systems: Publishing an international open access journal in a developing country. Proceedings of the 5th Belgrade International Open Access Conference, Belgrade; 2012.p. 101-12. Available from: http://boac.ceon.rs/public/full/5th-bioac.pdf. Accessed October 1, 2017.

5. Balhara YPS. Indexed journal: What does it mean? Lung India. 2012;29:193.

6. Dewan P, Gupta P. Writing the title, abstract and introduction: looks matter! Indian Pediatr. 2016;53:23541.

7. Hartley J. What's new in abstracts of science articles? J Med Libr Assoc. 2016;104:235-7.

8. Ware M. Universities' own electronic repositories yet to impact on Open Access. Nature Web Focus. Available from: http://www.nature.com/nature/focus/accessdebate/ 4.html?foxtrotcallback=true. Accessed October 1, 2017.

9. Zainab AN. Open access repositories and journals for visibility: Implications for Malaysian libraries. Malaysian J Libr Inform Sci. 2010;15:97-119.

10. Bleda AM, Aguillo IF. Can a personal website be useful as an information source to assess individual scientists? The case of European highly cited researchers. Scientometrics. 2013;96:51-67.

11. Chen C, Sun K, Wu G, Tang Q, Qin J, Chiu K, et al. The impact of internet resources on scholarly communication: A citation analysis. Scientometrics. 2009;81:459-74.

12. Barjak, F. The role of the Internet in informal scholarly communication. J Amer Soc Inform Sci Technol. 2006;57:1350-67.

13. Marcus B, Machilek F, Schütz A. Personality in cyberspace: Personal web sites as media for personality expressions and impressions. J Personality Soc Psychol. 2006;90:1014-31.

14. Weibel D, Wissmath B, Zroner R. Motives for creating a private website and personality of personal homepage owners in terms of extraversion and heuristic orientation. Cyberpsychology. 2010;4:5. Available at: https:// cyberpsychology.eu/article/view/4234/ 3278. Accessed September 30, 2017.

15. Anonymous. Get Noticed: Promoting Your Article for Maximum Impact. Elsevier. 2016. Available from: https:// www.elsevier.com/_data/assets/pdf_file/0013/201325/ Get-Noticed_Brochure_Sep2016.pdf. Accessed October 1, 2017.

16. Beel J, Gipp B, Wilde E. Academic Search Engine Optimization (ASEO): Optimizing scholarly literature for Google scholar and co. J Scholarly Publ. 2010;41:176-90.

17. Anonymous. Get Found. Optimize Your Research Articles for Search Engines. Elsevier, 2016. Available from: https:/ /www.elsevier.com/connect/get-found-optimize-yourresearch-articles-for search-engines. Accessed October 1, 2017.

18. Thelwall M, Kousha K. ResearchGate articles: Age, discipline, audience size and impact. J Assoc Information Sci Technol. 2017;68:468-79. 
19. Memon AR. Research Gate is no longer reliable: Leniency towards ghost journals may decrease its impact on the scientific community. J Pakistan Med Assoc. 2016;66:1643-47.

20. Atlas of Science. About Us. Available from: http://atlasof science.org/sample-page/. Accessed October 1, 2017.

21. Author Services. Share your e-prints. Available from: http:/ lauthorservices.taylorandfrancis.com/shareyour eprints/. Accessed October 1, 2017.

22. Springer Nature. Shared. Available from: $h t t p: / / w w w$. sprin gernature.com/gp/researchers/sharedit. http://www.wvj. science-line.com/wvj-pii.html. Accessed October 1, 2017.
23. Anonymous. Database Linking. https://www.elsevier.com/ authors/author-services/.../data-base-linking. Accessed October 1, 2017.

24. World's Veterinary Journal. Publisher Item Identifier. Available from: http://www.wvj. science-line.com/ wvjpii.html. Accessed October 1, 2017.

25. Open Researcher and Contributor ID. What is ORCID? Available from: https://orcid.org/about/what-is-orcid/ mission. Accessed October 1, 2017.

26. Casrai. CRediT: Contributor Roles Taxonomy. Available from: http://docs.casrai.org/CRediT. Accessed October 1, 2017. 